\title{
Erratum to: Effects of arboriculture stands on European hare Lepus europaeus spring habitat use in an agricultural area of northern Italy
}

Elisa Cardarelli • Alberto Meriggi • Anna Brangi •

Anna Vidus-Rosin

Published online: 27 July 2011

(C) Mammal Research Institute, Polish Academy of Sciences, Białowieża, Poland 2011

Erratum to: Acta Theriol (2011) 56:229-238

DOI 10.1007/s13364-010-0019-4

Due to a mistake the affiliation of the authors is wrong. The correct affiliation should read as follow:

E. Cardarelli $(\bowtie) \cdot$ A. Meriggi $\cdot$ A. Vidus-Rosin

Department of Animal Biology

University of Pavia

Via Ferrata 1

27100 Pavia, Italy

e-mail: elisa.cardarelli@unipv.it
A. Brangi
Wildlife Service
Provincial Administration of Pavia
Via Taramelli 2
27100 Pavia, Italy

The online version of the original article can be found at http://dx.doi. org/10.1007/s13364-010-0019-4.

E. Cardarelli $(\square) \cdot$ A. Meriggi $\cdot$ A. Vidus-Rosin Department of Animal Biology, University of Pavia, Via Ferrata 1,

27100 Pavia, Italy

e-mail: elisa.cardarelli@unipv.it

\footnotetext{
A. Brangi

Wildlife Service, Provincial Administration of Pavia,

Via Taramelli 2,

27100 Pavia, Italy
} 